\title{
SEPARATION OF POWERS AND
}

\section{POLITICAL ACCOUNTABILITY*}

\author{
Torsten Persson Gerard Roland Guido Tabellini
}

First version: June 15, 1996.

Final version: May 20, 1997

\begin{abstract}
Political constitutions are incomplete contracts and therefore leave scope for abuse of power. In democracies, elections are the primary mechanism for disci-

This research is supported by a TMR grant from the European Commission, by the Bank of Sweden Tercenterary Foundation and by the CNR. The present paper grew out of the work on the MEI-6 report (Dewatripont et al (1995)) and of conversations with Roger Myerson at the September 1995 ESF conference in Castel Gandolfo. We are grateful to David Baron, Olivier Blanchard, Mathias Dewatripont, Ed Glaeser, Fausto Pannunzi, Michele Polo, Patrick Rey, Andrei Shleifer, Jean Tirole, two anonymous referees, participants in the July 1996 CEPR summer workshop in Economic Theory, and to seminar participants at Harvard, Minneapolis, Rochester, Princeton, Columbia, NYU, BU, MIT, Brown, Paris, LSE, Toulouse, Stockholm, CES, Bocconi, Stanford and Berkeley for helpful comments. We are also grateful to Christina Lönnblad for editorial and secretarial assistance.
\end{abstract}


plining public officials, but they are not sufficient. Separation of powers between executive and legislative bodies also helps preventing the abuse of power, but only with appropriate checks and balances. Checks and balances work by creating a conflict of interests between the executive and the legislature, yet requiring both bodies to agree on public policy. In this way, the two bodies discipline each other at the voters' advantage. Under appropriate checks and balances, separation of powers also helps the voters elicit information. 
"If men were angels, no government would be necessary. If angels were to govern men, neither external nor internal controls on government would be necessary. In framing a government which is to be administered by men over men, the great difficulty lies in this: you must first enable the government to control the governed; and in the next place oblige it to control itself. A dependence on the people is, no doubt, the primary control on the government; but experience has taught mankind the necessity of auxiliary precautions.

This policy of supplying, by opposite and rival interests, the defect of better motives, might be traced through the whole system of human affairs, private as well as public. We see it particularly displayed in all the subordinate distributions of power, where the constant aim is to divide and arrange the several offices in such a manner as that each may be a check on the other - that the private interests of every individual may be a sentinel over the public rights. These inventions of prudence cannot be less requisite in the distribution of the supreme powers of the State". [J. Madison, The Federalist, number LI.] 


\section{Introduction}

One of the basic constitutional principles of liberal democracies is the separation of powers. Since the writings of Locke and Montesquieu, separation of the legislative, executive and judicial powers is deemed essential to avoid usurpation and tyranny by the holder of these powers. These ideas exerted a strong influence on the founding fathers of the American constitution. As the quote from Madison illustrates, they were convinced that separation of powers is a necessary precaution, even in a democracy that periodically elects its own rulers.

This principle is so much part of our political culture that we no longer question it. Yet, it is not immediately obvious why separation of powers is so important even in a democracy. Why is the threat of losing the elections not sufficient to discipline an omnipotent executive or legislature? What do we gain by separation of powers? What do we lose? How should this separation be designed? Even though all democracies have separation of powers, the balance of powers varies between the executive, the legislature, the judiciary, and the citizens. In particular, the executive and the legislature have different powers in presidential and parliamentary systems, but different constitutions also make these bodies more or less powerful, depending on how they structure the legislative process. ${ }^{1}$ 
Our general purpose is to address these basic questions with the tools of modern economic theory. We must, however, restrict ourselves to a subset of these difficult and fundamental questions, because they have so many dimensions involving the interactions between electoral systems and the organization of government. Elections, for instance, perform at least four distinct functions: (1) they aggregate and represent the voters' conflicting preferences; (2) they aggregate dispersed information about the correct political decisions; (3) they address an adverse selection problem by allowing the citizens to select the most competent individuals for public office; and (4) they provide a mechanism to control moral hazard, by holding elected officials accountable to the citizens. Similarly, the separation of powers can have many rationales, such as prompt correction of mistakes or protection of minorities.

In this paper, we only focus on achieving accountability through elections and separation of powers. This goal is shared widely by voters and we therefore abstract from the complications arising from voters having conflicting preferences, as for example in the case of redistribution. We also disregard how the separation of powers may affect electoral outcomes, such as the moderation of policies under divided government [Alesina and Rosenthal, [1995]]. Furthermore, we consider only the executive and legislative powers, ignoring the judicial power. ${ }^{2}$ 
When analyzing how well different constitutions help voters control their elected officials, we adopt the general approach of the principal-agent literature. But when applying this approach to the design of political constitutions, certain natural constraints must be respected. Real-world political constitutions are incomplete contracts: elected politicians are not offered an explicit incentive scheme associating well defined payoffs with actions in all states of the world. Political constitutions only specify who has the right to make decisions, and according to which procedures for which circumstances. This makes it hard to tie specific rewards or sanctions to the contents of those decisions. The mechanism to control a politician is to deny him the right to make those decisions in the future that is, to throw him out of office. In the terminology of Holmström [1982] and Tirole [1994], politicians can only be offered implicit incentive schemes. We ignore the more fundamental problem of why political constitutions are structured as incomplete contracts. We instead study how well different constitutions allow voters, constrained to such implicit incentive schemes, to reduce the rents captured by politicians.

What is the source of those rents? One is power: when citizens elect their leaders they temporarily delegate the exclusive decision-making authority over policymaking to the holders of public office. This creates scope for abuse of power 
between elections. The other source of rents is informational asymmetries: in many cases, policymakers have access to much better information on the relative merits and precise consequences of alternative policies than the population at large. This also creates scope for potential abuse by the holders of public office.

To model the distinctive features of different forms of democratic rule in a precise way, we treat the interaction between the executive and the legislature as a simple but completely specified extensive-form game. These constitutional rules dictate who can make a legislative proposal over what, whether that proposal can be amended and how, what happens when a proposal or an amendment is rejected, and so on. Our approach is therefore very much related to the rational-choice literature in American politics on structure-induced equilibria [Shepsle [1979]], on agenda-setting powers [Romer and Rosenthal 1979]], and on majoritarian legislative bargaining [Baron and Ferejohn [1989]].

A central result of the paper is that separation of powers improves the accountability of elected officials, and thereby the utility of voters, but only under appropriate checks and balances. The separation of powers allows the design of a system of checks and balances that fulfills two conditions: (i) there is a conflict of interests between the executive and the legislature, (ii) legislative decision-making requires joint agreement by both bodies. We model realistic decision-making processes 
that satisfy these two conditions. A particularly relevant application concerns the budget process. The voters benefit when the constitution splits the decisions over the budget into two separate stages, yet requires both policy-making bodies to agree at each stage. But one body (say the executive) has complete agenda setting power over the size of the budget, while the other (the legislature) has complete agenda setting power over its composition. This sequential structure enhances the voters' control of abuse. A mere conflict of interests between the executive and the legislature is, however, not sufficient to improve accountability. The key condition to make separation of powers work in favor of voters is that no policy can be implemented unilaterally, i.e. without the consent of both bodies. If public bodies with opposing interests could make independent claims on government resources, without any joint decision-making, the voters would suffer disastrous consequences. Separation of powers then worsens accountability by creating a - "common pool" problem. ${ }^{3}$

These results hold irrespective of the assumptions about the voters information, and follow from the incomplete contract framework. A second result of the paper is that the separation of powers also enables the voters to elicit the private information held by the elected political officials and hence to remove any informational rents. This finding is reminiscent of results in the mechanism- 
design literature. By inducing political bodies to compete against each other in an extensive-form game, an uninformed principal can extract information from them [Moore and Repullo [1988]]. For this result to hold, one of the two bodies must be given full agenda-setting power. If voters coordinate on an appropriate voting strategy, then the other body can be induced to reveal the information. But, as would be expected, this truth-telling equilibrium is not collusion proof.

A third result of the paper points to a crucial difference between Presidential and Parliamentary democracies: the procedure for appointing the executive is direct in a presidential system, but indirect, through the legislature, in a Parliamentary system. Direct control by the voters keeps the executive more accountable, as it minimizes the danger of collusion between the legislature and the executive over reappointment of the latter. Intuitively, when executive reappointment is decided by the legislature, it becomes harder for the voters to control moral hazard becomes harder. This problem of indirect versus direct control also arises in other situations such as when appointing judges and heads of administrative agencies. The model indicates that to break such collusion, the executive must be forced to step down after any legislative elections, a feature observed in every parliamentary democracy.

We believe that our results shed new light on the benefits of agenda-setting 
powers. Since McKelvey [1976], we know that agenda-setting avoids cycling in collective decision-making. Here, agenda-setting power proves crucial in the design of separation of powers. Our central result on checks and balances is based on separating a decision in parts and giving each body full agenda-setting power over his part of the decision. A conflict of interests can thus be created so that each body prevents the other from abusing his power. This feature drives the result on the benefits of a sequential decision making structure, as well as the result on information revelation. The extreme distribution of bargaining power implied by agenda-setting serves to align the interest of the weaker party in the decision with the interests of voters. To put it more colorfully: for accountability to work well, responsibilities must be clearly defined so that it is apparent whom to blame for a transgression.

In Section 2 we analyze the two sources of rents from office in a democracy by considering how voters can control a single elected body with executive powers: a "pure" presidential system. In Section 3, we analyze the first source of rents, namely the abuse of power, when a second elected body, the legislature, interacts with the executive. We first show how the separation of powers can worsen accountability, by creating a "common-pool" problem. When joint agreement on decisions is required, however, the outcome is better than in the pure presidential 
system. In particular, we show that an appropriate sequence of decision-making introduces checks and balances such that both the executive and the legislature are deprived of most of their rents from holding power. In section 4, we analyze the informational rents. We show how separation of powers between the executive and the legislature allows the voters to extract full information and therefore reach a higher utility, provided one of the two bodies is given full agenda-setting powers. In Section 5, we study the conditions for information revelation in parliamentary systems and to what extent our results are robust to collusion between the legislature and executive over reappointment of the latter. Section 6 concludes with suggestions for further research.

\section{A "Pure" Presidential System}

Throughout this section we assume that there is only one elected official, to whom we refer as the executive. For this reason, we call this political system a pure presidential system. We analyze the two sources of rents from office- power between elections and information - and we derive results that will serve as useful benchmarks when evaluating the results under separation of powers.

The model in this section is closely related to that in Ferejohn [1986], where an appointed agent exerts "effort" to please the principals (the voters), and derives 
exogenous utility from being in office. ${ }^{4}$ The main difference is that in this model we fully endogenize the utility from holding office, by assuming that the agent has an opportunity to divert resources from public to private use. What Ferejohn calls effort, we identify as abstaining from such diversion. There is thus no value of holding office per se, aside from the possibility of appropriating resources. We only study the conflict of interests between politicians and the voters created by such appropriation, and abstract completely from government activities where their interests are aligned. The appointed agent is disciplined by the voters through an intertemporal trade-off: if he diverts too much today, he is removed from office, and will not be able to appropriate resources tomorrow.

\subsection{The Model}

A large number of identical and infinitely lived voters maximize jointly the following expected utility function:

$$
E \sum_{t=0}^{\infty} \delta^{t} u\left(c_{t}\right)
$$

where $0<\delta<1$, where $E$ is the expectations operator, and where $u\left(c_{t}\right)$ is a concave utility function monotonically increasing in $c_{t}$. The voters' public good 
consumption $c_{t}$ is defined by:

$$
c_{t}=\theta_{t}\left(1-x_{t}\right)
$$

The parameter $\theta_{t}$ is a non-negative random variable, serially uncorrelated and identically distributed over time. It can be considered a productivity parameter translating budgetary resources into public goods provided to the consumers. At some points below, we will use specific examples, where we assume that the utility function is linear $u\left(c_{t}\right)=c_{t}$ and/or that $\theta_{t}$ is uniformly distributed over the interval $[0, \bar{\theta}]$

The variable $x_{t}$ is chosen by the executive. If $x_{t}>0$, the executive is diverting resources that otherwise would benefit the voters. If on the other hand $x_{t}<0$, the executive adds resources for the voters' benefit (i.e., $x_{t}<0$ can be interpreted as effort). One can think of $x_{t}$ as being related to the government budget. Certain types of government expenditures may allow more diversion of resources than others, or a majority of voters may favor a different composition of government spending than government officials. What $x_{t}$ captures is thus the conflicting interests between public officials and the general public regarding the composition of government expenditures, the firms involved in public procurement, the location 
of public projects, and so on. Implicit in (2) together with $c_{t} \geq 0$ is a resource constraint that limits the maximum amount that can be appropriated by the executive in each period, namely $x_{t} \leq 1 .{ }^{56}$ The executive maximizes the expected utility function

$$
E \sum_{t=0}^{\infty} \delta^{t} v\left(x_{t}\right)
$$

where $v(0)=0, v_{x}\left(x_{t}\right)>0, v_{x x}\left(x_{t}\right) \leq 0$ for all $x_{t}$. At some points below, we will use the special case $v\left(x_{t}\right)=x_{t}$. We have assumed that the discount factor of voters and the executive are the same, but that their utility functions are different. This conforms with the logic of the model (candidates for office are drawn at random from the population, and $c$ captures consumption of public goods, whereas $x$ is more like private consumption). But alternative assumptions on these points would not alter the substantive results.

Note that the model can still be given the same interpretation as the one in Ferejohn [1986] if we call $\left(1-x_{t}\right)$ effort, but then one must add an exogenous private benefit from being in power or, equivalently, a utility loss from losing office.

The sequence of events is as follows. At the start of each period $t$, voters choose a voting rule conditional on their information at the end of the period. Next the realization of $\theta_{t}$ is observed by the executive, who then chooses the 
action $x\left(\theta_{t}\right)$ knowing the voting rule. At the end of period $t$ the voters observe $c_{t}$ and, depending on whether there is full information or not, they may also observe the realization of $\theta_{t}$. Based on this observation and following the voting rule, the voters reappoint the executive or not. An executive thrown out of office is never reappointed. In this case an opponent is elected. There is always one available opponent, identical in all respects to the incumbent. Voters are thus generically indifferent between the incumbent and the opponent and any voting rule is (weakly) ex - post optimal. ${ }^{7}$ The only role of the opponent is to provide a costless alternative. We assume $x_{t}$ is not verifiable, even when $\theta_{t}$ is observable. Hence, the voters cannot prevent $x_{t}>0$; they can only punish the incumbent ex-post.

We assume that voters coordinate on the same reappointment rule. Throughout the paper we restrict our attention to sequentially rational equilibria in which every player chooses a pure strategy that conditions her decision on the outcome of the game in the current period and not in any previous period. The restriction to pure strategies makes sense for a large population: it is unrealistic to assume that voters could coordinate on implementing a strategy that made reappointment random from the viewpoint of the executive. If either the voters or the incumbent have strictly concave utility, then voters' welfare would be higher with a voting 
rule dependent on the history of past performance, and not only on events in the current period. Such a voting rule would complicate the analysis without changing the basic trade-offs we identify. Moreover, a history dependent voting rule would be optimal only under the assumption of commitment across periods. If voters reoptimize at the beginning of each period, as we assume, then it can be shown that the equilibrium voting rule cannot be history dependent. Finally, a simple retrospective voting rule has the additional advantage of plausibility. It can be thought of as a simple convention adopted by the voters, and suggested by a social norm. ${ }^{8}$ Since it is an equilibrium, it is self enforcing. Our analysis thus picks the best possible equilibrium from the voters' point of view in a restricted class of voting rules. It can therefore be seen as an analysis of the potential for efficient outcomes under alternative institutions.

\subsection{Rents from Power}

If the voters have full information about the state of nature $\theta$, by (2) they can observe the amount diverted by the executive. ${ }^{9}$ The executive can then be disciplined quite tightly: if he diverts too much, he is thrown out of office. Nevertheless, he must still be allowed to appropriate some resources. The reason is that, if the gains from holding office are too small, he would prefer to take as much as possible 
today, knowing that he will not be reappointed tomorrow. Holding power between two elections is thus a source of rent, even under full information. Proposition 1 tells us what is the maximum amount that the executive is allowed to appropriate in equilibrium:

\section{Proposition 1}

In equilibrium, the executive diverts $x^{F} \equiv v^{-1}[(1-\delta) v(1)], 0<x^{F}<1$. The voters adopt the voting rule: Reappoint the executive if and only if $c(\theta) \geq$ $c^{F}(\theta) \equiv \theta\left(1-x^{F}\right)$. The executive is reappointed, for all realizations of $\theta$.

To prove it, consider the proposed equilibrium voting rule. By (2), if the executive diverts more than $x^{F}$, he is thrown out of office. Let $V\left(\theta^{\prime}\right)$ be the equilibrium continuation value for the executive if he is reappointed, under this voting rule, tomorrow and the state of nature is $\theta^{\prime}$. He is indifferent between $x^{F}$ today together with reappointment, and 1 (the maximum diversion) today together with loss of office, if $x^{F}$ satisfies:

$$
v(1)=v\left(x^{F}\right)+\delta E V\left(\theta^{\prime}\right)
$$

The voters cannot reduce diversion below $x^{F}$, because then the executive would prefer to divert everything he could today and be thrown out. Conversely, voters 
have no interest in letting the executive appropriate more than $x^{F}$. Thus, $x^{F}$ denotes the minimum amount that the executive must be guaranteed. ${ }^{10}$

Equation (4) implies that, for all $\theta^{\prime}$, the value of being reelected is:

$$
V\left(\theta^{\prime}\right)=\frac{1}{1-\delta} v\left(x^{F}\right)
$$

Combining (4) and (5), we get the equilibrium amount $x^{F}$ defined in Proposition 1. Finally, by (2), the voters can hold the executive accountable to this behavior by adopting the voting strategy described in the Proposition.

The equilibrium is illustrated in Figure 1. In the case of linear executive utility $v(x)=x$, the equilibrium expressions for $x^{F}$ and $c^{F}(\theta)$ simplify to: $x^{F}=1-\delta$ and $c^{F}(\theta)=\delta \theta$.

It is easy to see that the amount of diversion depends on the time lapsed between two elections. Thus, if the executive was reelected only every two periods, then in the linear case, one easily computes that $x^{F}=1-\delta^{2}$ and $c^{F}(\theta)=\delta^{2} \theta$, implying higher diversion and lower welfare for voters. In this simple model of accountability, it is in the voters' interest to hold elections as frequently as possible to discipline the executive. Finally, and quite intuitively, the voters are better off the more far-sighted is the incumbent (i.e., the closer is $\delta$ to 1 ): if the future is 
not heavily discounted, the value of holding office increases, and this induces the incumbent to be more self-restrained while in office. This remark also applies to the next section on incomplete information.

\subsection{Rents from Incomplete Information}

Suppose now that the voters only observe $c$ but not $\theta$ and cannot discriminate between a small realization of $\theta$ and the executive deciding a budget with a high $x$. This case is analogous to that studied by Ferejohn [1986]. Here, the reappointment rule cannot be conditional on $\theta$, since it is unobserved. Given our assumption that voters condition reappointment only on current period performance, and not on that of previous periods, the reappointment rule will be a simple cut-off rule: if they observe $c \geq c^{*}$, then they reappoint the executive. But if $c<c^{*}$, they throw him out of office.

Faced with this voting rule, the executive seeks reappointment only if $\theta$ is sufficiently favorable. In this case, he gives the voters just enough to reach the minimum threshold, $c^{*}$. If , on the other hand, the realization of $\theta$ is too small, pleasing the voters is too hard for the executive, who may even be called upon to set $x<0$. Thus, for low values of $\theta$, the executive takes as much as possible today, knowing that he will not be reappointed. 
The equilibrium under incomplete information can be described as follows:

\section{Proposition 2}

If $\theta<\theta^{*}$, then $x(\theta)=1, c=0$, and the executive is thrown out of office.

If $\theta \geq \theta^{*}$, then $x(\theta)=1-c^{*} / \theta, c=c^{*}$, and the executive is reappointed.

The appendix contains the proof, and shows that in the special case of linear

utility and a uniform distribution $[0, \bar{\theta}]$ the threshold levels of $\theta$ and $c$ simplify to $\theta^{*}=\bar{\theta} / 2$ and $c^{*}=\frac{\bar{\theta} \delta}{2-\delta(1-\log 2)}$. This equilibrium is illustrated in Figure 2.

Clearly, the voters are hurt by the incomplete information, while the executive captures some informational rents. The expected value of holding office for the executive is higher than under full information, because the executive appropriates a larger share of the surplus at high realizations of $\theta$. When $c^{*}$ is optimally set by voters at the threshold value $\theta=\theta^{*}$, the executive must appropriate less than in the full information equilibrium: $x\left(\theta^{*}\right)<x^{F}$.

As with full information, voters would do better if we allowed them to commit to strategies conditional on a longer history than current performance [see the literature on repeated moral hazard, and in particular Rogerson [1985] and Chippori et al. [1994]]. It is not clear, however, whether this result would extend to our model with no commitment of voters, lack of explicit incentive schemes, and the restriction to pure strategies. Banks and Sundaram [1993, 1996] discuss 
related issues and study equilibria with simple cut-off rules in models of political accountability that combines moral hazard and adverse selection. All subsequent equilibria we consider have full information or complete information revelation, so these issues do not arise.

\section{Separation of Powers and Checks and Balances.}

We now modify the previous model by adding a second policymaker directly appointed by the voters. This second policymaker can be thought of as Congress in a Presidential system like the US, and this is the terminology we will use. The model can also be interpreted differently, however, as applying for instance to a Commitee structure in Congress, with the two political appointees being the chairs of two separate committes . In keeping with the rules of real-world presidential systems, both policymakers are directly appointed by the voters. The comparison between the presidential and the parliamentary system, where the executive is elected indirectly, is left to section 5 .

We continue to refer to decision-making process over the public budget as an example. With two policymakers, the constitution determines what power each body has at each stage of the decision-making process. Different budgetary procedures allow policymakers to divert different amounts of resources in equilibrium. 
We want to contrast alternative procedures. Voters do not observe who is diverting resources from them. They know the rules of decision-making, however. For the sake of realism, they can observe whether or not Congress and the Executive made a formal agreement, but this is not important for our argument.

The voters are described as in (1) above. But the budget constraint is now written as:

$$
c=\theta(1-x-l),
$$

where $x$ is still the amount appropriated by the executive $X$, whereas $l$ is the amount appropriated by Congress $L$ (for Legislature). Executive preferences still satisfy equation (3) and $L$, without loss of generality, is assumed to have an identical expected utility function:

$$
E \sum_{t=0}^{\infty} \delta^{t} v\left(l_{t}\right)
$$

Throughout this section we assume that voters can observe $\theta$, even though the results also hold with incomplete information. The evaluation of the separation of powers thus involves a comparison with the results of Proposition 1 . We show that the old idea of "checks and balances" induced by the separation of powers requires two conditions: (i) a conflict of interests between executive and legislature and 
(ii) their joint agreement in decision-making. In the following subsection, we show that when the former but not the latter condition is met, separation of powers makes voters worse off by creating a "common pool" problem.

\subsection{The Common-Pool Problem}

There is a common pool problem in public decision-making when a government body can independently commit public expenditures without requiring approval from other government bodies. ${ }^{11}$ In the context of separation of powers, this is a situation where, for example, the Executive can commit expenditures to defense, say, independently of Congress and Congress can independently commit expenditures to, say, road construction. In our model, this implies that each party can unilaterally divert resources without requiring the approval of the other.

These independent claims on resources must, however, collectively meet the total resource constraint of government. Commitments on each side must then be scaled down so as to satisfy the resource constraint. What matters for our results is not whether the total resource constraint is "hard" or "soft", but the fact that claims on resources made independently make it much harder for voters to discipline officeholders.

Consider the decision-making process depicted in Figure 3. Both the Executive 
and Congress bid for an amount of resources, denoted by $\widetilde{x}$ and $\widetilde{l}$. If $\widetilde{x}+\widetilde{l} \leq 1$, they get $x=\widetilde{x}$ and $l=\widetilde{l}$. If however $\widetilde{x}+\widetilde{l}>1$, they get $x=1 / 2$ and $l=1 / 2$. Thus there are no checks and balances: the only limit to appropriability of resources by each party is the total amount of resources available ( 1 in our case). For simplicity, we only consider the case of linear utilities, but the argument extends to more general utility functions as well. We then have:

\section{Proposition 3}

In a common pool situation, voters are worse off than under a pure presidential system.

To prove this, consider the following voting rule: reappoint both agents if and only if $c \geq \theta \lambda$. It is straightforward to see that there is always a disastrous equilibrium (for the voters) with $c=0$, where for any $\lambda>0$, both agents bid $\widetilde{x} \geq 1 / 2$ and $\tilde{l} \geq 1 / 2$ and get $x=l=1 / 2$. What about other equilibria more favorable to the voters ? Consider the best possible equilibrium for the voters where both political bodies make symmetric and compatible bids $\widetilde{x}=\tilde{l}=$ $(1-\lambda) / 2$. For this to be an equilibrium, $\lambda$ must be such that if one party, say $L$, bids $(1-\lambda) / 2, X$ must be indifferent between bidding $(1-\lambda) / 2$ and being reappointed, or bidding $\widetilde{x}=1-(1-\lambda) / 2$ but losing office. With linear utilities,

we must have: $1-(1-\lambda) / 2=\frac{(1-\lambda)}{2(1-\delta)}$. This implies $\lambda=\delta /(2-\delta)$. Note that bids 
must be symmetric to support this equilibrium. If $L$ would bid $2(1-\lambda) / 3$, for example, $X$ would be strictly better off bidding $\widetilde{x} \geq 1 / 2$; moreover, no party has an interest in bidding less than $(1-\lambda) / 2$. Now, as $\delta<1, \lambda=\delta /(2-\delta)$ implies that $\lambda<\delta$. Thus, we must have $c=\lambda \theta<\delta \theta$. Recall that in a pure presidential system with full information and linear utilities, equilibrium consumption for the voters is: $c^{F}(\theta)=\delta \theta$. Thus, even in the best equilibrium, voters are strictly worse off than in a pure presidential system. This result is robust to alternative assumptions on how the budget is split when the two bids exceed unity.

The idea that voters are worse off under the common pool problem is not surprising; the common-pool problem is a form of the "tragedy of the commons". A conflict of interests between the two appointed bodies does not reduce their equilibrium rents by itself. On the contrary, the inefficiency created by the common-pool situation gives them incentives to outbid each other, which makes it harder for the voters to discipline them. As shown in the next subsections, separation of powers helps the voters only if the executive and the legislature are forced to agree to a common policy. ${ }^{12}$

Note that the common pool problem is not entirely eliminated even if we give each agent independent control over a fixed share of the budget, unless the actions of both agents are separately observable. Specifically, suppose that the bidding 
game described above is replaced by the following assumptions: $\mathrm{X}$ independently sets $x$ subject to $x \leq \alpha$, and L sets $l$ subject to $l \leq 1-\alpha$ where $\alpha$ is a parameter. The voters know $\alpha$ and observe $c$ but cannot observe $x$ and $l$. It is easy to show that there remain multiple equilibria: a bad equilibrium where both agents divert as many resources as possible, expecting the other agent to do the same, and a good equilibrium essentially identical to that with a single appointed policymaker. Thus, giving independent control of a fixed share of the budget to each agent improves on the common pool situation in the good equilibrium, because it avoids a conflict of interest that is detrimental to the voters. But it does not get rid of the tragedy of the commons in the bad equilibrium.

\subsection{Checks and Balances}

We first show that once both policymakers are forced to agree on budgetary decisions, voters can be made as well off as under the pure presidential system and the tragedy of the commons disappears. We illustrate this with a case where the executive has agenda-setting power but we show that the logic of the argument is robust to changes in the bargaining power of the executive and legislature. For simplicity we continue to assume that $\theta$ is observable by the voters.

The sequence of events is illustrated in Figure 4. The Executive (the agenda 
setter) makes a budget proposal to Congress implying the amounts $(x, l)$. This proposal must satisfy $c=\theta(1-x-l) \geq 0$. The contents of this proposal need not be understood by voters, who only observe that a budget proposal is made. The important thing is that the diversion of resources $(x, l)$ necessitates acceptance of the Executive's budget proposal by Congress. The latter cannot make any amendments, but must either accept or reject the proposal; we have a closed rule to use the jargon of the legislative bargaining literature. If Congress accepts, the proposal is implemented. Otherwise, a status quo policy is implemented where both policymakers obtain a predetermined amount:

$$
x=x^{S}, l=l^{S} \text {, where } x^{S}<\delta \text { and } l^{S}<1-\delta,
$$

Finally, at the end of each period, the voters reappoint (or do not reappoint) any of the two policymakers, knowing, $c, \theta$ and whether the Executive proposal is accepted or rejected ${ }^{13}$.

Thus, in contrast to the common pool situation, the two agents cannot make independent claims on budgetary resources. The specific details of bargaining are unimportant. Similar results would apply if both agents had veto rights over the buget, or if the rents are shared according to a given sharing rule. What matters is 
that the policy must be jointly approved, and once approved it binds both agents.

The status quo payoffs $x^{S}$ and $l^{S}$ could be equal to zero but need not be. In various countries, the status quo could be interpreted as the outcome if no budget is approved. In this case, ministries and administration are run on provisional monthly budgets which are typically smaller than the size of approved budgets. But if $x^{S}+l^{S}$ is sufficiently close to zero, the status quo would be in the best interest of voters in this model. The model could easily be change so that voters are also hurt by the status quo, i.e. by a breakdown of government decisionmaking. We could assume that if the status quo is reached, voters would get $c=$ $\theta\left(1-x^{S}-l^{S}-s\right)$, with $s$ sufficiently large. Voters could force the government bodies to reach a decision, by conditioning reappointment also on agreement between the two political bodies.

Our assumed legislative process is very stylized, but captures the idea that in many Presidential systems the executive is an agenda setter, while the main role of Congress is to approve or to reject a proposal. Alternatively, the model could also be interpreted as referring to different commitees in Congress, which must all approve the policy before it is implemented, and which have different agenda setting or bargaining powers. In section 4, we consider an alternative process, which is closer to the US situation, where Congress can make amendments and 
the executive has veto power.

As voters know $\theta$ they know $c$, and thus the overall amount diverted. What is the maximum that voters can expect to get in each period, for a given $\theta$ ? Under the closed rule we have assumed, the Executive has maximum power in the legislative bargaining game. With the retrospective voting rule below, however, Congress can ensure re-election by voting no to any executive proposal and triggering the status quo. We therefore conjecture that in equilibrium the Executive gets all the rents, while Congress is nailed to its status quo payoff: $l=l^{S}$. Based on this conjecture, we derive the equilibrium of the game by considering the incentives of the players at each stage of a typical period. We start from the end, i.e. from the voting rule.

Given that the voters know $\theta$, they must let the Executive appropriate the minimum amount at which he prefers to be reappointed rather than grab as much as possible today and then be thrown out. Let $x^{F}$ denote this minimum amount (a precise definition of $x^{F}$ is given below). By (6), the maximum amount the voters can expect is thus:

$$
c^{F}(\theta)=\theta\left(1-x^{F}-l^{S}\right)
$$


To achieve this, voters must discipline Congress and the Executive through an appropriate voting rule. It is natural to consider a reappointment rule similar to the one in the Section 2.2, namely:

Reappoint the Executive and Congress if and only if $c \geq c^{F}(\theta)$

Consider next the choices of the executive. Under voting rule (R1), the Executive has two options. One option is to seek reappointment by presenting the Congress with the budget $\left(x^{F}, l^{S}\right)$. Under (R1), this offer is accepted by Congress, and both policymakers are reappointed. Congress would reject any other proposal that maintained $l=l^{S}$ and attributed $x>x^{F}$ to the executive, to avoid losing office. The second option is to convince Congress to enjoy the short run benefits and accept the loss of office. To achieve this, the executive must offer Congress more than $l^{S}$. Define $l^{A}$ as:

$$
v\left(l^{A}\right)=v\left(l^{S}\right)+\delta E V^{L}\left(\theta^{\prime}\right)
$$

where $V^{L}\left(\theta^{\prime}\right)$ is the continuation value of the game for Congress, when holding office in state $\theta^{\prime}$. The offer $l^{A}$ is a budget deal such that Congress is just indifferent 
between diverting $l^{A}$ and being sacked by the voters, or rejecting the offer, getting the status quo $l^{S}$ and being reappointed. Under the equilibrium voting rule if Congress were presented with an offer infinitesimally higher than $l^{A}$, it would always accept, whereas it would accept an offer smaller than (or equal to) $l^{A}$ only if that did not prejudice reappointment. Solving equation (10) for $l^{A}$, we get:

$$
l^{A}=v^{-1}\left[\frac{v\left(l^{S}\right)}{1-\delta}\right],
$$

which reduces to $l^{A}=\frac{l^{S}}{1-\delta}$ when $v(\cdot)$ is linear. Being forced to give Congress $l^{A}$, under the assumption that both will be ousted, reduces what the Executive can divert for himself, and reduces the short-run benefits of diversion relative to the long run benefits of retaining office. Let $x^{F}$ be defined implicitly by the following condition:

$$
v\left(1-l^{A}\right)=v\left(x^{F}\right)+\delta E V^{X}\left(\theta^{\prime}\right)
$$

The left-hand side measures the short run payoff for the Executive of grabbing everything left, after a minimum acceptable offer to Congress, knowing that this would result in loss of office. The right-hand side measures the payoff of diverting $x^{F}$ only and being reappointed next period. To prevent the Executive from bribing Congress, he must be allowed to divert at least $x^{F}$ every period. Combining (11) 
and (12), we get

$$
\begin{gathered}
x^{F}=v^{-1}\left[(1-\delta) v\left(1-l^{A}\right)\right]= \\
=v^{-1}\left[(1-\delta) v\left(1-v^{-1}\left[\frac{v\left(l^{S}\right)}{1-\delta}\right]\right)\right],
\end{gathered}
$$

which for linear utility $v($.$) simplifies to: x^{F}=\left(1-\delta-l^{S}\right)$.

We are now ready to state the following result:

\section{Proposition 4}

There is an equilibrium with full information over $\theta$, where the Executive proposes the budget $\left(x^{F}, l^{S}\right)$, with $x^{F}$ defined by (13). This proposal is accepted by Congress and implemented. The equilibrium is supported by the voting rule

(R1) according to which both policymaking bodies are reappointed.

To verify that this is indeed an equilibrium, consider the payoffs from unilateral deviations. Faced with a budget from the Executive satisfying the voters, i.e. diverting $x^{F}+l^{S}$, Congress could not strictly gain from a rejection, since it would continue to get only $l^{S}$. To induce Congress to accept a more diversive budget than in the proposed equilibrium, the Executive would have to offer $l>l^{A}$. But by definition of $x^{F}$, the Executive has no incentive to make such an offer. Thus, neither policymaker stands to gain from unilateral deviations. Given that the voters know $\theta$, policy-makers would not gain from a joint deviation. The equilibrium 
of proposition 4 can thus also be sustained if no restriction is imposed on the deals the two policymakers can make among themselves. Under full information over $\theta$, the equilibrium is thus collusion proof and robust to differences in bargaining power between executive and legislature. Finally, the voters are unable to improve on this equilibrium. They would then have to try and reduce the Executive's rents below $x^{F}$, since Congress is already nailed to the status quo. But this would be counterproductive, because the Executive would then have an incentive to bribe Congress with an offer that could not be refused.

Note that with linear utility $v(\cdot),(9)$ and (13) imply $c^{F}(\theta)=\delta \theta$, the same expression we obtained under full information in the pure presidential system. Even though it is impossible to observe who is diverting resources, the voters can hold both policymakers accountable just as much as a single policymaker. In this model, there is only one reason for a policymaker to refrain from excessive diversion of resources today: to be able to continue holding office and diverting some resources tomorrow. This basic intertemporal trade-off is not altered substantially by the presence of a second policymaker, and with linear utility it is not altered at all. 


\subsection{Two-Stage Budgeting}

In the previous section, the requirement of joint decision making weakens the bargaining power of the agenda setter in a way that can be exploited by the voters. This suggests that a stronger conflict of interest between the two political bodies might further reduce the power of the agenda setter and benefit the voters. The main result of this section is that appropriate separation of powers can indeed make the voters better off than under a pure presidential system. This example is again related to realistic budgetary procedures. By appointing two agents rather than one and appropriately separating their decision-making power over two separate stages of the budgetary process, the voters can pit one agent against the other and exploit the resulting conflict of interests.

Consider the following two-stage budgetary procedure under a presidential system as depicted in Figure 5. In the first stage, the Executive proposes to the legislature a total amount of diverted resources $g$. As $g$ may vary with the size of the budget, this can be seen as a proposal of a budget size. The legislature can either approve it or reject it, in which case a status quo of $g^{S}$ prevails. In the second stage, Congress proposes the allocation of the budget, implying a split of the diverted resources $(x, l)$ between the two bodies. The budget size cannot be renegotiated at this stage. We thus have $x+l=g$ or $g^{S}$, depending on whether $g$ 
was approved or not in the first stage. The Executive can either approve or reject the proposal over $(x, l)$. If the proposed allocation is rejected, the outcome is the status quo allocation $\left(x^{S}, l^{S}\right)$, with $x^{S}+l^{S}=g^{S}$.

The key idea here is that the decisions on the overall size of the budget and on its composition require the consent of both bodies, but the agenda-setting power over each decision rests with a different body. This creates a conflict of interests that favors the voters. More precisely, in the last stage of the budgetary process, Congress makes a take it or leave it offer that nails the Executive to its status quo payoff. Anticipating this outcome, in the first stage the Executive has a strong incentive to propose a budget size that pleases the voters enough to promise him reappointment. Increasing the budget size above the voters' cutoff would enable Congress to appropriate more resources, but the Executive would only stand to lose, since it would not be reappointed and has no bargaining power at the allocative stage. The suggested procedure thus curtails the Executive's power (when compared to the one-stage procedure studied in the previous section).

To state our results more precisely, we need some new notation. Let $x^{R}$ and $l^{R}$ be the amounts that leave the Executive and Congress indifferent between receiving these amounts for ever, and grabbing the status quo payoffs once and 
accepting electoral defeat:

$$
\begin{aligned}
& x^{R}=v^{-1}\left[(1-\delta) v\left(x^{S}\right)\right] \\
& l^{R}=v^{-1}\left[(1-\delta) v\left(l^{S}\right)\right] .
\end{aligned}
$$

Clearly, these amounts are strictly smaller than the status quo payoffs, $x^{S}$ and $l^{S}$, and hence also smaller than the amounts appropriated in the full information equilibrium described above and in section 2. Consider a voting rule that promises reappointment if and only if Congress and the Executive together do not appropriate more resources than the sum of these amounts. Specifically:

Reappoint the executive and Congress if and only if $c \geq c^{R}(\theta)=\theta\left(1-x^{R}-l^{R}\right)$.

We then have:

\section{Proposition 5}

In equilibrium the Executive proposes $g^{R} \equiv x^{R}+l^{R}$, Congress proposes $\left(x^{R}, l^{R}\right)$, and both proposals are accepted. Voters follow rule (R2) and are made strictly better off than under a pure presidential system. 
The proof is straightforward. For a given $g>g^{R}$ agreed upon in the first stage, both agents lose office under voting rule (R2). Hence, it is always in the interest of $L$ to propose $l=g-x^{S}$ in the second stage, as $X$ would veto any offer smaller than $x^{S}$, and would accept anything at least as large as $x^{S}$. Thus, by proposing $g>g^{R}, X$ loses office and gains at most the status quo payoff $x^{S}$ for one period, irrespective of whether or not his offer is accepted by $L$ (remember that if $L$ rejects, then $g=g^{S}>g^{R}$ ). If instead $g=g^{R}$ is agreed upon in the first stage, then $X$ either receives $x^{S}$ and is sacked by the voters (if in the second stage $L$ makes an unacceptable offer to $X$ ), or receives $x^{R}$ forever (if, in the second stage, $L$ acts as in the proposed equilibrium). By definition of $x^{R}$ and $l^{R}$, both agents weakly prefer the proposed equilibrium. Hence, having agreed to $g^{R}$ in the first stage, the two agents get $x^{R}$ and $l^{R}$ in the equilibrium continuation of the second stage. Finally, if presented with an offer $g=g^{R}$ in the first stage, $L$ is indifferent between accepting it and rejecting it, again by definition of $l^{R}$. Hence, $X$ weakly prefers to make such an offer and then be reappointed by the voters, rather than to propose a larger budget, obtain $x^{S}$ and lose office immediately thereafter. Thus, neither the Executive nor Congress gain by unilaterally deviating from the proposed equilibrium. Finally, by $(14), x^{R}$ and $l^{R}$ are both strictly smaller than the status quo payoffs, which are in turn smaller than the amounts appropriated 
in the full information equilibria of the previous sections. In the case of linear utilities, the voters get $c^{R}(\theta)=\theta\left(1-(1-\delta)\left(x^{S}+l^{S}\right)\right)>\theta \delta \equiv c^{F}(\theta)$ as $x^{S}+l^{S}<1$.

The important insight that emerges from Proposition 5 is that the budget decisions should be separated in two stages. Congress should have all the agenda setting power over one stage, the Executive should have it over the other stage; and the consent of both agents should be needed to approve both stages. Since Congress has all the bargaining power over the composition of the budget, the Executive's interest is aligned with the voters'. The voters can then rely on the Executive to discipline Congress by proposing a small budget. ${ }^{14}$

Note that by imposing a sequential procedure, we make it impossible for Congress (who has the agenda setting power in the allocative stage) to promise the Executive a favorable composition, in return for a large budget in the first stage. Such a promise would not be credible under the assumptions of this game, because once the size of the budget is approved, Congress would renege on its promise and exploit its agenda setting power to implement its preferred allocation. ${ }^{15}$

The result of Proposition 5 relies on only one of the two bodies (Congress in that example) being the residual claimant of a larger budget. This, in turn, occurs because the status quo payoff for the other party (the Executive), $x^{S}$, is independent of the budget size, $g$. Suppose instead that, if disagreement is 
reached in the second stage of the game in Figure 5, the policymakers share the budget according to some predetermined sharing rule. This would be the case with repeated sequential bargaining over the allocation of the budget. Specifically, suppose that the status quo payoffs in the second stage are defined as $x^{S}=\gamma g$ (or $\gamma g^{S}$, depending on the outcome of the first stage) and $l^{S}=(1-\gamma) g\left(\right.$ or $\left.(1-\gamma) g^{S}\right)$, for some given parameter $0<\gamma<1$. Then, separation of power does not serve any purpose: the equilibrium is equivalent to that of a pure presidential system, under the same informational assumptions.

To see this, assume that voting rule (R2) is followed and Congress and the Executive are both ousted whenever $c<\theta\left(1-g^{R}\right)$. Suppose, for the moment, that the Executive's offers are accepted by Congress (we verify below that this is true about the Executive's optimal offer). The Executive could either propose $g=1$, receive $x^{S}=\gamma$ in the second stage and be ousted jointly, or propose $g^{R}$, receive $\gamma g^{R}$ in the second stage, and be reelected. To prefer the latter strategy, it must be that:

$$
v(\gamma)<\frac{v\left(\gamma g^{R}\right)}{1-\delta}
$$

With linear utility (a slightly more complicated argument applies for concave 
utility), this implies $1-\delta<g^{R}$, which contradicts the previous definition of $g^{R}$. Hence, the Executive prefers proposing $g=1$. One can apply the same argument to show that Congress also prefers to accept rather than to refuse the proposal of the Executive. For any $\gamma>0$, the voting rule (R2) could thus not discipline both policymakers. Voters would have to concede a joint per period rent of $1-\delta$, as in voting rule (R1). Thus, by appointing a second policymaker, they cannot improve upon the pure presidential system.

One way to understand this result is to note that status quo payoffs proportional to the approved size of the budget make both bodies residual claimants in the second stage. The prerogative of Congress to propose a share of the budget in the second stage then loses significance and deprives Congress of some of its power over the allocation: the Executive can secure at least a share $\gamma$ of the budget in any case. When, on the other hand, the status quo $x^{S}$ is independent of the size of the approved budget, a bigger budget size is fully appropriated by Congress. This is why the Executive then has no incentive to propose a bigger budget.

The general implication of this analysis is that the budgetary procedure should be designed so as avoid both bodies being residual claimants over the budget. One can then discipline both policymakers by structuring the decision-making process so that the body that is not residual claimant acts in the interests of voters. Giving 
full agenda-setting power to one body and making sure that it can nail the other body to a given status quo payoff is in the voters' interest. A process that instead fosters cooperation, and implies a sharing rule as a the default alternative, removes the prospective benefits of competition among the appointed policymakers. ${ }^{16}$

We have analyzed the checks and balances by two-stage budgeting in the context of separation of powers between the legislature and the executive. But the same general principle also applies to other aspects of the separation of powers. An alternative application might be to require approval of the opposition parties (i.e. unanimity or qualified majority) for the total budget and to let the majority coalition decide on its composition.

\section{Separation of Powers and Information Revelation.}

We now assume that voters cannot observe $\theta$. The details of the political process are often so complex and behind the scene that voters do not have an informed opinion on many issues. What the voters ultimately know is how well off they are, who is responsible for making a proposal, and whether that proposal was accepted. Moreover, the voters also see an unstructured public debate about the policy consequences, typically through the media, where the parties involved take some definite position. Suppose thus that the voters cannot observe $\theta$ at all, 
whereas both policymaking bodies can do so without cost. The question we now ask is whether the benefits of separation of powers also hold in these circumstances, and if there are additional benefits besides those in the previous sections.

The game is of the form given in Figure 6. It is exactly the same as the one of Proposition 4, except that we add an initial announcement stage where both policymakers separately and simultaneously announce $\theta^{L}$ and $\theta^{X}$ (the superscript indicates who makes which announcement). The announcement stage can be thought of as a required report - a state of the union address, or a senate hearing. But it can also be thought of as a preliminary public debate, in the course of which Congress and the Executive make some assessment of exogenous circumstances or of the policy consequences. The legislative stage involves a sequence of offers and counteroffers by the agenda setter and the legislature, that eventually results in a budget and a policy outcome.

Can the voters exploit the conflict of interest between Congress and the executive to extract information about $\theta$ ? The answer is positive, provided that one agent has full agenda-setting power and that they cannot collude. The voters can indeed gain information by exploiting the announcement stage. Redefine the 
threshold level of consumption defined in (9) as

$$
c^{F}\left(\theta^{L}\right)=\theta^{L}\left(1-x^{F}-l^{S}\right)
$$

and let the voters' reappointment rule (R1) refer to this new threshold. If $\theta^{L}=\theta$, the equilibrium is identical to the full information equilibrium described in Section 3.2. In such an equilibrium, the amount appropriated by Congress is always $l^{S}$, irrespective of its announcement. But then, Congress is indifferent between lying or not. Announcing the true state of the world $\theta$ is thus an equilibrium (though not the only one). If Congress were to lie, and announce $\theta^{L}<\theta$, the executive might propose a budget more favorable to himself, while leaving Congress at the status quo payoff. With closed rule legislative bargaining, Congress would have no incentive to reject such a proposal. Hence, all benefits from a false announcement would be appropriated by the executive. We summarize this discussion as follows:

\section{Proposition 6}

When $\theta$ is not observed by the voters, the full information equilibrium can still be attained, if voters condition their reappointment rule on Congress announcement, $\theta^{L}$, according to (R1) and (16). Under this voting rule, there exist an equilibrium where Congress makes a truthful equilibrium announcement: $\theta^{L}=$ 
$\theta$.

Thus, by appointing a second policymaker interacting with the executive under the assumed political rules, the voters can be made strictly better off compared to the pure presidential system. The reason is that the announcement of the weaker political agent reveals additional information. The legislative game gives all power to the executive, who becomes the residual claimant on the informational rents. By an appropriate choice of voting rule, the conflicting interests of Congress can then be naturally aligned with those of the voters. This is why Congress reveals the information. Note that this equilibrium disappears if Congress is given some bargaining power or if the status quo outcome for both policymakers is an increasing function of $\theta$, because then Congress shares the informational rents with the executive. Our result thus provides a second rationale for political institutions giving all agenda-setting power over a decision to a single body (here the executive). ${ }^{17}$ We know since McKelvey [1976] that agenda-setting power is an important device to prevent the non-existence of voting equilibria. Here, we see that under separation of powers, giving full agenda-setting power to one body improves accountability via information revelation. This result, together with the one on checks and balances, shed new light on the role of agenda-setting.

What matters for the above result is not who has agenda-setting power but 
that one body is given full agenda-setting power over a well-defined decision. Consider now a political system where the relative political powers of the legislature and the executive have been reversed. An example would be to let the legislature amend the proposal by the executive, and give the latter veto rights over amendments. If the veto is exercised, the status quo is implemented. In this modified game, the legislature is the residual claimant on informational rents, but the voters can still enforce the full-information equilibrium, by conditioning their voting rule on the executive's announcement. This is formally proved in a previous version of the paper.

The general emerging result is thus that separation of powers benefits efficiency because it induces revelation of information. The less powerful political body reveals the information, and the details of the legislative process determine who is less powerful.

If the separation of powers reveals information, could one not achieve the same objective by having an independent agency monitor the executive and gather information on $\theta$ ? Press independence already plays this role to a certain extent. We would, however, argue that instead of making separation of powers redundant, independent media strengthens its usefulness. First, the executive and the legislature typically have privileged access to information, if only through their 
exercise of power and their official functions. It would thus be very costly for an independent agency to acquire the same amount of information. Moreover, information that leaks to the press typically comes from the arcanes of power. Suppose, though, that this information could indeed be gathered independently, perhaps at a cost. Suppose also that-just after the announcement stage in our model - the true $\theta$ is announced to the general public with positive probability (however small). Suppose finally that voters punish $L$ by ousting it for lying. Then $L$ is not only indifferent between lying and truth-telling, but is strictly better off by announcing the truth. This would clearly eliminate non-truth-telling equilibria.

Truth-telling equilibria cease to exist if the Executive and Congress can collude over the announcement, however. If a binding agreement could be made over the announcements and the budget allocation, the powerful political actor would have obvious incentives to compensate the other body for not telling the truth with a sweet budget proposal $\left(l>l^{S}\right)$. With such agreements possible, we would essentially be back in the situation of Section 2, with one political body.

How plausible is such collusion over the announcements? We think that a binding agreement over the announcements might be considerably more difficult to sustain than other types of collusion, such as over the possible acceptance 
of the budget. Whereas the latter is a well-specified, observable and verifiable event, announcements are more difficult to enforce since they could be made implicitly in the context of the political debate or might be the result of informal discussions with the media. Even if promises on announcements could be enforced, an agreement where the politically powerful body gave up some informational rents in exchange for a false announcement would not be ex post optimal. Once the announcements were made, the strong political body would gain from deviating and holding the weak body down to its status quo payoff.

Note that the timing of the announcements is critical. If announcements were only made after the policy was approved, even the weak agent would have an incentive to announce a low realization of $\theta$ to ensure reappointement. Anticipating this, the agenda-setter could bid for more resources for himself, breaking the equilibrium. Thus the voters should optimally restrict their voting rule to be conditional only on information revealed before the proposal stage.

Repeated interactions between the Executive and Congress would, however, invite self-enforcing collusion between the two bodies supported by reputational forces. We have ruled this out by not allowing history dependent strategies. Investigating what kind of constitutional rules would make such collusion more difficult in a richer framework of asymmetric information, is an interesting issue for 
further research. ${ }^{18}$ Term limits, for at least one of the bodies - although they would unambiguously hurt the voters in the framework of this paper - may perhaps serve this purpose.

\section{Parliamentary Systems}

A central aspect of the Presidential systems described in the previous section is that both policymakers are directly accountable to the voters. This direct accountability is lost in a Parliamentary system, where the executive is directly accountable to the legislature, and only indirectly to the voters. What are the relative gains, or losses, of such an indirect appointment procedure, compared to the direct procedure in a Presidential system? And how should the appointment rules be designed, to minimize the danger of collusion between the two political agents? Naturally, the distinction between direct and indirect appointment procedures is relevant even under alternative interpretations of the model. For instance, judges and other public officials are appointed in different ways in different countries. These questions are addressed in this section.

We first show that a Parliamentary and a Presidential system are equivalent under appropriate appointment rules: information revelation by the weak political party is a feature of both systems; and the opportunities for collusion are the 
same and concern the announcement stage. The informational equivalence is not very surprising. In the context of this paper, where we discuss the control of moral hazard, separation of power is essential to the revelation of information, and this separation can be achieved in both political systems. It remains to be investigated whether this informational equivalence generalizes to other contexts, like the control of adverse selection - that is, selection of more competent incumbents.

The second kind of equivalence, concerning the opportunities for collusion, is more delicate. It rests on a central institutional feature observed in virtually every Parliamentary system, namely that the executive is forced to step down at any Parliamentary election. As we shall see, it is this feature that prevents collusion between Parliament and the Executive over the appointment decision.

\subsection{Separation of Powers in a Parliamentary Democracy}

We now adapt the model and sequence of events in subsection 3.2. to a Parliamentary system. We shall refer to the legislature (still denoted by $L$ ) as Parliament rather than Congress. The sequence of events is similar until Parliament has accepted or rejected the Executive offer and the policy has been implemented. After this, Parliament votes on a motion of confidence to the executive. Upon observing the outcome of Parliament's decision, Parliamentary elections are held. 
If the Executive is ousted by Parliament, then it is excluded from power for ever. Parliament can be reappointed or not, at the voters' discretion. But if the motion of confidence is won, the Executive can only be reappointed if Parliament is also reappointed. That is, if the incumbent legislature loses the elections, its decision to reappoint the executive is void, and neither the previous executive nor the incumbent legislature can ever be reappointed. Thus our model implicitly incorporates the assumption that, as in Norway, elections are held at a fixed date; not affected by the outcome of the confidence vote. The sequence of events (with full information) is illustrated in Figure 7.

Even though this assumed sequence of events does not exactly correspond to the formal rules of Parliamentary democracies, it nevertheless captures some of their fundamental features. In most Parliamentary democracies, the legislature has the option of bringing down the government at any point in time. Moreover, an incumbent legislature may appoint its candidate prime minister just before the elections, but if the elections are lost, it is denied the right of appointing the government in the subsequent legislature. Stated otherwise, a Parliament cannot appoint a government to last beyond itself, and any government is forced to step down at the end of a legislature. This constraint is natural in the context of government appointment, but perhaps not in other instances of delegated 
appointment. Subsection 4.2 investigates the consequences of relaxing this constraint and allowing for collusion over reappointment. Finally, we are implicitly assuming that, if a legislative majority has designated a candidate for prime minister before legislative elections, it does indeed appoint the designated candidate if the elections are won. This assumption is also plausible.

As before, we start with the assumption that the realization of $\theta$ is observed by the voters. Thus, at the time of Parliamentary elections, the voters can infer the overall amount diverted, by observing $c$. They do not observe who appropriated what (even though in equilibrium they can guess it correctly). No specific assumption on whether the voters also observe the outcome of Parliament's decision concerning the executive reappointment, or Parliament's reply to the executive offer, is required. But it is clearly most realistic to assume that both decisions by Parliament are observed.

A natural extension of voting rule (R1) to this new setting is:

$$
\text { Reappoint Parliament if and only if } c \geq c^{F}(\theta) \text {. }
$$

It is easy to show that:

\section{Proposition 7}


Under voting rule (R3), the equilibrium is identical to that described in Proposition 4.

As in section 4, the executive has all the bargaining power, but Parliament has strong incentives to reject budget proposals that would lead to its removal. In particular, any executive proposal with $x>x^{F}$ and $l \leq l^{A}$ would be rejected by Parliament to avoid being ousted by the voters. Hence, the executive would never make such a proposal, since it would lead to the status quo outcome (recall that $x^{F}>x^{S}$ ). If $x>x^{F}$ and $l>l^{A}$ are proposed by the executive, they would be accepted by Parliament. But then, under voting rule (R3), Parliament loses the elections. In this case, by assumption, the executive is also removed from office. By definition of $x^{F}$, however, the executive does not want to make such an offer; it prefers instead to appropriate just $x^{F}$ and remain in office.

It is important to stress that, under the stated assumptions, there is no scope for collusion between Parliament and the executive over executive reappointment. Even if the executive could make an offer to Parliament conditional on being reappointed, the voters would still be able to oust the executive by voting Parliament out of office. Indeed, the voting rule (R3) only conditions on the voters payoffs, and not on Parliamentary decisions. This point is further elaborated in the next subsection. 
Finally, by repeating the argument in Section 4, it is easy to show that this equilibrium allocation can also be achieved if the voters do not observe $\theta$, but instead condition their vote on the truthful announcement $\theta^{L}$.

\subsection{Collusion over Executive Reappointment}

The previous equilibrium relied on a critical feature of the appointment rules: a Parliament ousted by the voters also forces the Executive to step down. To better understand the role of this feature, and the consequences of abandoning it, we now consider a political appointment procedure where this constraint is not imposed. The model is thus identical to that of the previous subsection, with one exception. A decision by Parliament not to oust the Executive now remains valid notwithstanding the electoral outcome. As incomplete information is not essential to our argument, we assume that the voters observe the realization of $\theta$.

Let us start with the same no-collusion assumption as in the previous subsection. Thus, the executive proposal is not conditioned on a reappointment decision by Parliament. This implies that the outcome of the appointment decision must be ex post optimal for Parliament. Under this assumption, the results of Proposition 7 above continue to hold, under the same voting rule (R3). The argument is as follows: To induce Parliament to accept a more diversive budget than in the 
proposed equilibrium, and be sacked by the voters, the Executive must offer Parliament $l>l^{A}$. By definition of $x^{F}$, the Executive is willing to make such an offer only if it is sure of being reappointed next period. But, accepting the Executive offer of $l>l^{A}$, Parliament has no incentive to reappoint the executive. Indeed, Parliament is indifferent between calling a vote of non confidence or not, since it will be sacked by the voters anyway. Hence, there is an equilibrium (though not the only one) in which Parliament always sacks the Executive if it expects to be ousted by the voters. Expecting this strategy, the Executive is not willing to present Parliament with an offer $l>l^{A}$, and the equilibrium of Proposition 7 and 4 is sustained.

This is a very fragile equilibrium, however, that can easily be broken if the Executive and Parliament collude and make deals conditional on the executive reappointment. Suppose the Executive makes a proposal $(x, l)$ conditional on a binding promise of reappointment by Parliament. The equilibrium described in Propositions 4 and 7 can then not be sustained under any voting rule. The executive would propose Parliament a budget with $x>x^{F}$ and $l>l^{A}$, in exchange for a promise of reappointment. ${ }^{19}$ Parliament would accept. And the executive would be reappointed, even if Parliament was sacked. To prevent this collusive behavior, the voters would have to let the executive divert more, as stated in the 
following:

\section{Proposition 8}

To prevent collusion over reappointment, the Executive must be allowed to appropriate the amount $x^{C}=1-l^{A}$

To prove this, note that the Executive would always be able to induce Parliament to make a reappointment, by offering an amount infinitesimally higher than $l^{A}$. Having a reappointment promise, the Executive would then appropriate everything left (i.e., $1-l^{A}$ ) and bear no punishments. To discipline the Executive, voters must allow a diversion of at least $x^{C}$. Thus, the threshold value for voters now becomes:

$$
c^{C}(\theta)=\theta\left(1-x^{C}-l^{S}\right) \equiv \theta\left(l^{A}-l^{S}\right)
$$

and the voting rule that supports the equilibrium is:

$$
\text { Reappoint Parliament if and only if } c \geq c^{C}(\theta) \text {. }
$$

Faced with this voting rule, the Executive has no further incentive to bribe Parliament and the latter is left to consume its status quo payoff $l^{S}$. Naturally, in this equilibrium, both policymakers are always reappointed.

Compared to the equilibrium without collusion opportunities, voters are clearly 
worse off: $c^{C}(\theta)=\theta\left(1-x^{C}-l^{S}\right)<c^{F}(\theta)=\theta\left(1-x^{F}-l^{S}\right)$, as $x^{C}>x^{S}$. How much worse off depends on parameters and functional forms. In the case of linear utilities, it is easy to show that

$$
c^{C}(\theta)=\theta l^{S} \delta /(1-\delta)<\delta \theta=c^{F}(\theta)
$$

where the inequality follows from the assumption that $l^{S}<(1-\delta)$. Quite intuitively, voters are made worse off without the constraint that a resigning legislature cannot appoint a government for a new term of office. This constraint, which exists in virtually all parliamentary democracies, can thus be given a strong efficiency rationale. This is an example of a general point made by Tirole [1992], namely that what is interesting about collusion is not necessarily that it takes place in equilibrium, but that an organization is likely to adapt to the possibility that it may occur.

Indirect appointment procedures are not uncommon in the political system of Western democracies when it comes to other appointments. For instance, judges of the Supreme Court are often appointed by the president or by the legislature. Similarly, the board of directors of public enterprises or of independent public agencies, are generally not appointed by voters. Instead, this appointment is 
delegated to political appointees. In the case of these indirect appointments, there is often no constraint that requires the appointee to step down with the incumbent legislature or government. An important example of the absence of this constraint is the case of the European Commission. The above results suggest that these procedures may invite collusion, at the expense of the voters, between the appointees and the political body that appoints them. To further investigate this possibility is an interesting topic for further research. ${ }^{20}$

\section{Concluding Remarks}

It would be relevant to extend our analysis in several directions. Within the confines of the existing model, we have already mentioned the desirability to study self-enforcing (as opposed to enforceable) collusion between the executive and the legislature. It would also be desirable to study milder forms of asymmetric information: for instance, the executive and the legislature could both receive a noisy signal of the state of nature, possibly at a cost. A more demanding, but interesting, extension would be to formally analyze outside monitoring, say, by the media. Given the incentives for collusion between the politicians and the media, an important issue would be what type of political structure would be more likely to preserve the independence of the media. Finally, we have already mentioned how 
the appointments of other holders of public office by political appointees give scope for collusion. Studying the interplay between implicit incentive schemes given to legislators and to the heads of public agencies, appointed by these legislators to regulate private industry, would be an interesting extension of the recent literature on the political economy of regulatory capture [Laffont and Tirole [1993]].

Another fruitful extension, which requires more economic content to the model, would be to further explore the benefits of sequential decision-making and other checks and balances in the budgetary process for the promotion of fiscal discipline. This could help identifying more precisely critical features of budgetary procedures in empirical work. Persson, Roland and Tabellini (1997) explore this direction.

We have focused on the joint capacity of elections and the separation of powers to discipline the abuse of power by political leaders at the expense of the ordinary citizen. How important is this problem in reality? Clearly, such abuse often under the guise of non-transparent decision making - is a major feature of many developing countries. As these countries try to strengthen their democratic institutions, reforms that introduce clearer separation of powers can help limit the extensive rent-seeking within government, if they also provide the right checks and balances. What about the developed Western democracies? In some, abuse of political power may not appear to be a major problem (at least to most observers). 
A possible reason is that these countries indeed have useful political institutions, in line with our analysis in this paper. But recent experience with corruption and lack of accountability in countries such as Belgium, Italy, and Japan indicates that the problem is relevant also in the developed world. ${ }^{21}$ Another relevant problem is how to increase the accountability and transparency of decisions in the European Union: witness the handling of the mad-cow disease by the European Commission.

We would nevertheless like to extend our analysis of the benefits from the separation of powers, by allowing elections to have other functions than the control of moral hazard. If voters and their representatives are heterogenous, elections and subsequent legislative decisions also have to aggregate conflicting interests into public policy. Broadly speaking, this is likely to weaken the disciplining role of elections, as voters would have to trade off their individual preferences against efficiency in any disciplining voting strategy. With conflicting interests between voters and between their political representatives, we could also meaningfully address another distinction often made between presidential and parliamentary systems, namely the distinction between single-person and multiple-person executives.

It would also be natural to study adverse selection, arising from political can- 
didates having different competency in delivering efficient outcomes for the voters [as in Rogoff [1990]], or moral hazard together with adverse selection [as in Banks and Sundaram [1993, 1996]]. Adverse selection would potentially give rise to an interesting tradeoff between presidential and parliamentary systems. Specifically, the indirect accountability of the executive in a parliamentary system, would allow for more timely removal of an incompetent executive, but that possibility may lower the effective discount factor for the executive and thus distort investments in administrative competency or policy decisions with longer-term costs and benefits. These final comments suggest that the scope for a fruitful, formalized comparison between parliamentary and presidential systems is considerable. More research should follow. 


\section{APPENDIX}

Proof of Proposition 2: The value $\theta^{*}$ is defined as the level of $\theta$ at which the executive is indifferent between diverting 1 and being ousted or diverting $1-\frac{c^{*}}{\theta^{*}}$ and being reappointed. We thus have:

$$
v(1)=v\left(1-\frac{c^{*}}{\theta^{*}}\right)+\delta E V\left(\theta^{\prime}\right)
$$

In other words,

$$
\theta^{*}=\frac{c^{*}}{1-v^{-1}\left[v(1)-\delta E V\left(\theta^{\prime}\right)\right]}
$$

Below $\theta^{*}$, the executive is better off choosing $x=1$ (so that $c=0$ ) and above $\theta^{*}$, he strictly prefers choosing $x(\theta)=1-\frac{c^{*}}{\theta}$ so as to reach $c=c^{*}$. Voters thus choose $c^{*}$ so as to maximize

$$
\frac{1}{1-\beta} u\left(c^{*}\right)\left(1-F\left(\theta^{*}\right)\right)=\frac{u\left(c^{*}\right)}{1-\beta}\left[1-F\left(\frac{c^{*}}{1-v^{-1}\left[v(1)-\delta E V\left(\theta^{\prime}\right)\right]}\right)\right] .
$$


Differentiating this expression with respect to $c^{*}$ yields:

$$
\frac{u\left(c^{*}\right)}{u^{\prime}\left(c^{*}\right)}=\frac{1-F\left(\theta^{*}\right)}{f\left(\theta^{*}\right)}\left[1-v^{-1}\left(v(1)-\delta E V\left(\theta^{\prime}\right)\right)\right]
$$

which, under linear utility, together with the expression for $\theta^{*}$ implies:

$$
\theta^{*}=\frac{1-F\left(\theta^{*}\right)}{f\left(\theta^{*}\right)}
$$

For a uniform distribution of $\theta$, this yields $\theta^{*}=\frac{\bar{\theta}}{2}$. Together with linear utility, we have that

$$
E V\left(\theta^{\prime}\right)=F\left(\theta^{*}\right)+\int_{\theta^{*}}^{\bar{\theta}}\left(1-\frac{c^{*}}{\theta}\right) d F(\theta)+\left(1-F\left(\theta^{*}\right)\right) \delta E V\left(\theta^{\prime}\right)
$$

Taking into account that $F\left(\theta^{*}\right)=1 / 2$ and that $\left(1-\delta\left(1-F\left(\theta^{*}\right)\right)\right)=1-\delta / 2$, we have that

$$
E V\left(\theta^{\prime}\right)=\frac{1}{2-\delta}+\frac{2}{2-\delta} \int_{\theta^{*}}^{\bar{\theta}}\left(1-\frac{c^{*}}{\theta}\right) d F(\theta)
$$

Using the fact that $c^{*}=\theta^{*} \delta E V\left(\theta^{\prime}\right)=\frac{\bar{\theta}}{2} \delta E V\left(\theta^{\prime}\right)$, we have

$$
E V\left(\theta^{\prime}\right)=\frac{1}{2-\delta}+\frac{2}{2-\delta}\left(1-F\left(\theta^{*}\right)-\frac{\bar{\theta}}{2} \delta E V\left(\theta^{\prime}\right) \int_{\theta^{*}}^{\bar{\theta}} \frac{d F(\theta)}{\theta}\right)
$$




$$
\begin{aligned}
& =\frac{1}{2-\delta}+\frac{2}{2-\delta}\left(\frac{1}{2}-\frac{\delta}{2} E V\left(\theta^{\prime}\right) \log 2\right) \\
& =\frac{1}{1-\frac{\delta}{2}(1-\log 2)} .
\end{aligned}
$$

Note that $E V\left(\theta^{\prime}\right)>1$ so that the executive gets informational rents from the asymmetry of information. It is then immediate to get

$$
c^{*}=\frac{\bar{\theta}}{2} \frac{\delta}{1-\frac{\delta}{2}(1-\log 2)} .
$$

INSTITUTE FOR INTERNATIONAL ECONOMIC STUDIES, HARVARD UNIVERSITY, CEPR AND NBER

UNIVERSITE LIBRE DE BRUXELLES, ECARE AND CEPR BOCCONI UNIVERSITY, IGIER AND CEPR 


\section{REFERENCES}

Alesina, A., and R. and Perotti, "Budget Deficits and Budget Processes," NBER Working Paper, No 5556, 1996.

Alesina, A. and H. Rosenthal, Partisan Politics, Divided Government and the Economy, (Cambridge, Massachusetts, Cambridge University Press, 1995).

Austen-Smith, D., and J. Banks, "Electoral Accountability and Incumbency," in P. Ordeshook (ed.), Models of Strategic Choice in Politics, (Ann Arbor, University of Michigan Press, 1989).

Banks, J., and R. Sundaram, "Adverse Selection and Moral Hazard in a Repeated Elections Model,” in W. Barnett et al (eds), Political Economy: Institutions, Information, Competition and Representation, (New York, Cambridge University Press, 1993).

Banks, J., and R. Sundaram, "Electoral Accountability and Selection Effects," mimeo, University of Rochester, 1996.

Baron, D., and J. Ferejohn, "Bargaining in Legislatures," American Political Science Review, LXXXIII (1989), 1181-1206.

Barro, R., "The Control of Politicians: An Economic Model," Public Choice, XIV (1973), 19-42.

Brennan, G., and A. Hamlin, "A Revisionist View of the Separation of Powers," 
Journal of Theoretical Politics, VI (1994), 345-368.

Chiappori, P.A., I.Macho, P.Rey and B. Salanié , "Repeated Moral Hazard: the Role of memory, Commitment and the Access to Credit Markets", European Economic Review, 38 (1994), 1527-54

Dewatripont, M. et al., Flexible Integration: Towards a More Effective and De-mocratic Europe, MEI 6 report, (London, CEPR, 1995).

Diermeyer, D. and R. B. Myerson, "Lobbying and Incentives for Legislative Organization," mimeo, Stanford University, 1995.

Ferejohn, J., "Incumbent Performance and Electoral Control," Public Choice, L (1986), 5-26.

Gallagher, M., Laver, M. and P. Mair, Representative Government in Modern Europe, (New York, Mc Graw Hill, 1992).

Gilligan, T., and K. Krehbiel, "Organization of Informative Committees by a Rational Legislature," American Journal of Political Science, XXXIV (1990), $531-564$.

Holmström, B., "Managerial Incentive Problems: A Dynamic Perspective" in Essays in Economics and Management in the Honor of Lars Wahlbeck, (Helsinki, Swedish School of Economics, 1982).

Lewis-Beck, M., Economics and Elections: The Major Western Democracies, 
(Ann Arbor, University of Michigan Press, 1988).

Laffont, .J-J., and D. Martimort, "Separation of Regulators Against Collusive Behavior," mimeo, Toulouse, IDEI, 1996.

Laffont, J.-J., and J. Tirole, A Theory of Incentives in Procurement and Regulation, (Cambridge, MIT Press, 1993).

Lijphart, A., (ed.), Parliamentary versus Presidential Government, (Oxford, Oxford University Press, 1992).

Lijphart, A., Electoral Systems and Party Systems: A Study of Twenty-Seven Democracies, (Oxford, Oxford University Press, 1994).

McKelvey, R., "Intransitivities in Multidimensional Voting Models and Some Implications for Agenda Control," Journal of Economic Theory, XII (1976), 472482.

Moore, J., and R. Repullo, "Subgame Perfect Implementation," Econometrica, LXI (1988), 1191-1220.

Persson, T, G. Roland and G. Tabellini, "Public Finance, Accountability and Comparative Politics", mimeo, IGIER, 1997

Rogerson, W., "Repeated Moral Hazard," Econometrica, vol. LIII (1985), 69-77. Rogoff, K., "Equilibrium Political Budget Cycles," American Economic Review, LIII (1990), 21-36. 
Romer, T., and H. Rosenthal, "Bureaucrats vs. Voters: On the Political Economy of Resource Allocation by Direct Democracy," Quarterly Journal of Economics, ICIII (1979), 563-587.

,$-(1983)$.

Shepsle, K., "Institutional Arrangements and equilibrium in multidimensional voting models," American Journal of Political Science, XXIII (1979), 27-59.

Shleifer, A., and R.W. Vishny, "Corruption," Quarterly Journal of Economics, CVIII (1993), 599-617.

Shugart, M., and J. Carey, Presidents and Assemblies, (Cambridge, Cambridge University Press, 1992).

Tirole, J., "Collusion and the Theory of Organizations," Ch. 3 in J-J. Laffont (ed), Advances in Economic Theory 6th World Congress, Vol. II., (Cambridge, Cambridge University Press, 1992).

—, "The Internal Organization of Government," Oxford Economic Papers, XLVI (1994), 1-29.

von Hagen, J., and I. Harden "Budget Processes and Commitment to Fiscal Discipline," mimeo, University of Mannheim, 1995. 


\section{Footnotes}

1. Even though there is a huge literature on comparative politics, it is mostly descriptive. See in particular the comprehensive surveys by Lijphart $(1992,1994)$ or Gallagher et al.(1994), as well as Shugart and Carey (1992). We are only aware of a couple of contributions (see below) that attempt a formalized treatment of the separation of powers and of its role under various forms of democracy.

2. As we will, in fact, assume that all constitutional rules are respected, it is perhaps more plausible to say that we, implicitly, assume an independent and benevolent judiciary capable of enforcing these rules, but not capable of verifying and preventing all abuse of power.

3. One of the few formalized treatments of the separation of powers (that we are aware of) can be found in a recent paper by Brennan and Hamlin (1994), who argue that a functional division of powers between the executive and the legislature hurts voters. But the decision-making structure Brennan and Hamlin consider indeed splits decision-making between the two bodies without any checks and balances.

4. Ferejohn, in turn, built on earlier work by Barro (1973). Austen-Smith and Banks (1989) extend these analyses of political accountability to allow for incumbency effects. 
5. The advantage of this multiplicative formulation over an additive one ( $\left.c_{t}=\theta_{t}-x_{t}\right)$ is that the resource constraint facing the policymaker is not stochastic, which simplifies the algebra (below, we comment on where an additive formulation would make a difference).

6. It would be easy to provide a useful role for government in the model. For instance, we could assume that without a government, $c_{c}=0$. But it would clearly be more satisfactory to base our argument on a more complete model , incorporating policy dimensions where the interests of voters and politicians are conflicting as well as aligned.

7. If candidates for office are heterogeneous, and differ for instance in their competence, it may introduce adverse selection. This would definitely change the nature of the equilibria, because the voters would no longer be indifferent ex post between incumbents and (untested) opponents. See Banks and Sundaram (1993) for a model with both moral hazard and adverse selection.

8. Retrospective voting strategies, conditional on economic outcomes, also have empirical support (see, for instance, Lewis-Beck (1988)).

9. By our restrictions on strategies the environment will effectively be stationary. We therefore omit time subscripts in the following when there is no risk of confusion. 
10. If the constraint (2) were additive instead of multiplicative, the maximum diversion would instead be equal to $\theta$ and $x^{F}$ would have to be state dependent. Note also that if both the voters and the executive have concave preferences, it would be optimal to share risk among them, rather than have the voters bear all the risk. This can be sustained as an equilibrium only if voters could commit to a history dependent voting rule, however.

11. Von Hagen and Harden (1995) and Alesina and Perotti (1996) contrast the budgetary procedures of different countries, paying particular attention to the "common pool" problem.

12. Shleifer and Vishny (1993) and Diermeyer and Myerson (1995) analyze another form of free-riding related to the separation of powers. Essentially, those papers apply the double marginalization argument of industrial organization to corruption. Shleifer and Vishny study the bribing of separate agencies, whereas Diermeyer and Myerson study lobbying with separate chambers and variable legislative hurdles. Brennan and Hamlin (1994), in their study of the separation of powers, apply a similar argument.

13. Assuming that voters cannot observe whether the executive proposal is accepted or rejected by Congress would not change the results, unless the status quo is inefficient for the voters-see below. 
14. Persson, Roland and Tabellini (1997) extend this idea to a more detailed model of the budget, where the level of taxation and the composition of spending are decided sequentially and by separate political appointees.

15. This suggests that it is essential for the voters to be able to enforce a two stage procedure to discipline both policymakers. Naturally, with incomplete information, this could be more problematic. This in turn is an argument in favor of transparent procedures that minimize the scope for breaking the sequential nature of the budgetary process. See Alesina and Perotti (1996) for a discussion of budget transparency. Repeated interaction between the two agents could also make it possible to sustain collusion among them and side-step the two-stage budgeting process.

16. Romer and Rosenthal (1983) present a different but related argument about the optimality of giving full agenda setting power to a self selected policymaker.

17. The logic of Proposition 6 also applies to our case of checks and balances, where both agents each have full agenda-setting power over one decision. In that case, both can be induced to a truthful announcement since the conflict of interests between them nails both to their status quo payoff.

18. Laffont and Martimort (1996) argue, in a different context, that separation 
of powers between different regulatory agencies may limit the collusion between these agencies and the firms they regulate.

19. Since by assumption $l^{S}<1-\delta$, this offer does not violate the budget constraint.

20. Interestingly, direct elections of public officials seem much more common in the US than in European democracies.

21. Interestingly, the political system in all of these countries, has helped keep certain parties in office during virtually the whole post-war period despite many shifts in government (the Christian Democrats in Belgium and Italy and the LDP in Japan). Accountability may well have suffered. 